\title{
DINÂMICA DOS COMPOSTOS DE ENXOFRE EM UMA REPRESA DA ZONA RURAL DE MONTE BELO, MINAS GERAIS, BRASIL
}

\author{
Fabrício Santos Gonçalves de OLIVEIRA \\ Gustavo de Souza PESSÔA \\ Fábia Aparecida Rabelo da FONSECA \\ Lidiane Raquel Verola MATAVELI \\ Maria Jose dos Santos WISNIEWSKI \\ Célio WISNIEWSKI \\ Pedro Orival LUCCAS*
}

*Instituto de Química, Universidade Federal de Alfenas, CEP 37130-000, Rua Gabriel Monteiro da Silva, no 714, Centro, Alfenas, MG, Brasil, e-mail: pedro.luccas@unifal-mg.edu.br

Recebido em: 29/04/2014 - Aprovado em: 03/08/2015 - Disponibilizado em: 30/10/2015

\begin{abstract}
Resumo:
Foram feitas determinações de sulfato e sulfeto em amostras de água de uma represa localizada na Fazenda Lagoa, Instituto Sul-mineiro de Proteção Ambiental, Monte Belo, Minas Gerais. A concentração média de sulfato foi 13,47 ppm. Obtiveram-se concentrações para sulfeto de 5,5 a 14,3 ppb. Nota-se estratificação da coluna d'água na represa e correlação entre os teores de compostos de enxofre, parâmetros físico-químicos e teores de ferro e alumínio. Variações sazonais típicas do ecossistema foram observadas. Os processos de oxirredução constituem importantes mecanismos de reciclagem do enxofre na represa, postulando-se que sejam típicos desse ambiente, i.é., lagoa mesotrófica.
\end{abstract}

Palavras-chave: enxofre; especiação química, Análise em fluxo contínuo

\section{DYNAMIC OF SULFUR COMPOUNDS IN WATERS OF A DAM LOCATED IN RURAL ZONE OF MONTE BELO, MINAS GERAIS, BRAZIL}

\begin{abstract}
:
They were made sulfate and sulfide determinations in water samples collected in a dam located in Fazenda1 Lagoa, Monte Belo, Minas Gerais, Brazil. The mean concentration of sulfate was 13,47 ppm. It was obtained concentrations for sulfide, of 5,5 to $14,3 \mathrm{ppb}$. Stratification of the column of water is noticed in the dam and correlation among the composed of sulfur, physical-chemical parameters and tenors of iron and aluminum. Typical seasonal variations of the ecosystem were noticed. The oxirreduction processes constitute important mechanisms of sulfur's recycle in the dam, being postulated that they are typical that environment, mesotrophic lake.
\end{abstract}

Keywords: sulfur, chemical speciation, Flow Injection analysis.

\section{INTRODUÇÃO}

O enxofre é um dos mais abundantes elementos químicos na natureza. Os maiores reservatórios globais são a atmosfera e a litosfera. Está presente em rochas subterrâneas e minerais ou em sedimentos oceânicos profundos. Ocorre no estado nativo ou elementar e combinado com Fe e metais básicos. No petróleo o enxofre é encontrado em uma variedade de compostos orgânicos complexos e no gás natural como sulfeto de hidrogênio (KOMARNISKY, 2003). 
Alguns aspectos que influenciam as concentrações de enxofre em águas naturais são a litologia regional, aplicação de fertilizantes utilizados na agricultura, a precipitação atmosférica úmida e seca e principalmente a combustão de produtos industriais (ESTEVES, 1998).

Em plantas, homens e animais o enxofre ocorre em várias estruturas biológicas, estando presente no tecido corporal como parte dos aminoácidos metionina e cisteína, entre outras funções importantes no nosso organismo, fazendo parte da estrutura de coenzimas, vitaminas, agentes redutores e hormônios (KOMARNISKY, 2003).

Há muitas incertezas com relação às fontes, reações e destino das espécies de enxofre na atmosfera. Os compostos de enxofre entram na atmosfera em grande parte através da atividade humana, principalmente na forma de dióxido de enxofre $\left(\mathrm{SO}_{2}\right)$ que é um dos cinco maiores poluentes do ar no mundo. As principais fontes antropogênicas de emissão deste gás são a queima de combustíveis fósseis e as atividades industriais, tais como o refino do petróleo, indústria de cimento, metalurgia. A atividade vulcânica é a principal fonte responsável pelas emissões naturais de $\mathrm{SO}_{2}$. A queima da biomassa também tem sido considerada uma importante fonte de enxofre atmosférico em regiões continentais, especialmente nos trópicos (MARTINS, 2002).

A concentração de enxofre em lagos tem aumentado consideravelmente nos últimos anos. Este aumento tem sido observado não somente nos lagos localizados em regiões industrializadas, mas também naqueles distantes de centros urbanos e industriais. $\mathrm{O}$ transporte de gases e material particulado na atmosfera, contendo enxofre, e a sua posterior precipitação com as chuvas, tem sido apontado como a principal causa para o aumento da concentração de enxofre nos lagos, ocasionando uma acidificação destes, podendo levar a vegetação, peixes e outros organismos à morte (ESTEVES, 1998).

Uma vez emitido, o dióxido de enxofre gasoso pode reagir com vários oxidantes presentes na atmosfera e formar sulfato, na forma de gotas de $\mathrm{H}_{2} \mathrm{SO}_{4}$ ou em formas neutralizadas tais como sulfato de amônio. $\mathrm{O}$ processo de oxidação do $\mathrm{SO}_{2} \mathrm{e}$ outras espécies de S(IV) ocorrem tanto em fase gasosa em dias claros, como também em fase aquosa, na presença de nuvens e nevoeiros. Este gás exibe uma boa solubilidade em água, em comparação com outros gases presentes na atmosfera, o que resulta em um enriquecimento de S(IV) na água de chuva, nuvens e neblina (MARTINS, 2002). 
O sulfato é a mais estável e abundante forma de enxofre disponível para uso dos organismos vivos na biosfera. A maior parte da assimilação feita pelos organismos vivos é sobre esta forma que é liberada durante a decomposição da matéria orgânica sob a forma de $\mathrm{H}_{2} \mathrm{~S}$ (KOMARNISKY， 2003 \& WETZEL, 1983). Sendo um dos principais componentes de águas naturais, sua determinação é de interesse particular com respeito aos problemas de poluição de água e de chuva ácida, e para estudos geoquímicos e ambientais relacionados ao transporte de enxofre com sulfato dissolvido do ambiente terrestre para o marinho ou domínios lacustres. Além disso, o uso industrial difundido de ácido sulfúrico torna a determinação de sulfato importante para proteção ambiental (MIRÓ, 2004).

Vários métodos analíticos têm sido propostos para a determinação do sulfato, e isto se justifica, pois este íon é amplamente distribuído na natureza. Na forma oxidada de sulfato, o $\mathrm{S}$ constitui o segundo ânion mais abundante na água do mar (após o cloreto) e dos rios (após o bicarbonato). A determinação rápida e simples dos íons sulfato em águas naturais, especialmente em águas de chuva, tornou-se extremamente importante sob o ponto de vista ambiental e agronômico
Alguns outros compostos contendo enxofre como sulfetos e sulfitos também são descritos na literatura como poluentes presentes principalmente em efluentes industriais (MINISTÉRIO, 1986). O sulfeto está presente em nascentes especialmente, em fontes quentes. Sua presença comum em águas residuais vem em parte da decomposição de matéria orgânica, às vezes de águas industriais, mas a maioria da redução bacteriana do sulfato (CLESCERI, 1998). Em ambientes arejados ele é oxidado rapidamente sendo encontrado em concentrações baixas. Próximo do sedimento o $\mathrm{H}_{2} \mathrm{~S}$ reage com $\mathrm{Fe}^{2+}$ formando $\mathrm{FeS}$ insolúvel, podendo também complexar com outros elementos como cobre, zinco e chumbo e formar sulfetos mais insolúveis (WETZEL, 1983).

As reações que envolvem o ciclo do enxofre afetam acentuadamente os ciclos de outros nutrientes, a produtividade do ecossistema e a distribuição da biota. As exigências nutritivas da biota são satisfeitas pela abundância e distribuição geral dos compostos que contêm enxofre. O ciclo do enxofre é caracterizado por espécies químicas em variadas condições, pelas influências biológicas sobre as transformações das espécies de enxofre e pelo transporte deste elemento no sistema (WETZEL, 1983). Qualquer alteração neste ciclo pode afetar consideravelmente a (CRNKOVIC, 2002). 
biota local e os ciclos de outros elementos importantes para os organismos vivos.

\section{Descrição da área de estudo}

A represa na qual foi realizada a pesquisa está localizada na Fazenda Lagoa, dentro do Instituto Sul-mineiro de Proteção Ambiental localizado no município de Monte Belo, na região sul de Minas Gerais, aproximadamente nas coordenadas: $21^{\circ} 24^{\prime}$ de latitude $S, 46^{\circ} 16^{\prime}$ longitude $\mathrm{W}$ e a altitude média é $878 \mathrm{~m}$.

De acordo com Weyland (1990), a Fazenda Lagoa (fig. 1) é banhada principalmente pelo córrego Lagoa que deságua no ribeirão Inhumas, este é afluente do rio Muzambo que está represado pela hidrelétrica de furnas no município de Areado. A hidrografia dessa região se caracteriza como parte da subbacia do rio Grande, integrante da bacia do Paraná. O córrego da Lagoa é o principal corpo d'água da fazenda e, com suas ramificações, é o responsável pela imensa riqueza em recursos hídricos desta área.

A represa tem uma área aproximada de $3000 \mathrm{~m}^{2}$, sendo que a distância média da nascente do Córrego da Lagoa até a represa é de $10000 \mathrm{~m}$. Nesse percurso, foi observado extensa plantação de café, canade-açúcar e algumas plantações de banana. Estas atividades agrícolas podem ser responsáveis por trazer para este ecossistema, adubos, fertilizantes, pesticidas e outros interferentes químicos que determinariam concentrações marcantes dos analitos estudados.

Este trabalho teve como objetivos: Determinar as espécies de enxofre: sulfato e sulfeto em amostras de água; Fazer inferências sobre a influência dos analitos pesquisados no ecossistema estudado.

\section{MATERIAIS E MÉTODOS}

\section{Materiais}

\section{Equipamentos}

No presente trabalho foram utilizados os seguintes equipamentos: Balança Analítica Sartorius ${ }^{\circledR}$; Bomba peristáltica Ismatec ${ }^{\circledR}, 8$ canais; Cabos de Tygon para a propulsão dos fluidos; Cabo de polietileno (d.i. 0,8 $\mathrm{mm}$ ) para o transporte dos fluídos; Condutivímetro tipo caneta, Q-405 C, Quimis ${ }^{\circledR}$; Eletrodo de calomelano, Analyser ${ }^{\circledR}$; Eletrodo de platina; Espectrofotômetro Femto $^{\circledR}$ (UVVis), modelo 482, equipado com cubeta de fluxo; Sistema de purificação de água, Mili - Q Academic, Millipore ${ }^{\circledR}$; Injetor comutador 2:3:2 (CENA - USP); Interface PCL-711 $\quad\left(\right.$ Advantech $\left.^{\circledR}\right) ; \quad$ Peagâmetro 
portátil handLab $1, \mathrm{CE}^{\circledR}$; Termômetro de mercúrio Incotherm ${ }^{\circledR}$.

\section{Reagentes}

Segue uma relação dos reagentes empregados: Acetado de Zinco $\left(\operatorname{SIGMA}^{\circledR}\right)$; Ácido Clorídrico MERCK ${ }^{\circledR}$; Álcool Polivinílico (PVA) $\left(\right.$ SIGMA $\left.^{\circledR}\right)$; Cloreto de Bário $\left(\mathrm{REAGEN}^{\circledR}\right)$; Cloreto férrico hexahidratado $\left(\mathrm{SYNTH}^{\circledR}\right)$; EDTA Alcalino $\left(\right.$ MERCK $\left.^{\circledR}\right) ; \quad$ Hidróxido de Sódio $\left(\mathrm{QUIMEX}^{\circledR}\right) ; \quad$ N,N-diethyl-pphenylediamine $\left(\right.$ SIGMA $\left.^{\circledR}\right)$; Sulfato de Ferro II $\left(\right.$ VETEC $\left.^{\circledR}\right)$; Sulfeto de Sódio nonahidratado $\left(\right.$ SIGMA $\left.^{\circledR}\right)$.

\section{Metodologia}

\section{Coleta das amostras}

As amostras de água foram coletadas mensalmente no período de abril a outubro. $\mathrm{Na}$ represa estudada $\left(21^{\circ}\right.$ $24,671^{\prime} \mathrm{S}$ e $46^{\circ} 15,758^{\prime} \mathrm{W}$ ) foram três locais: próximo a principal entrada de água da represa (aproximadamente 1,25 $\mathrm{m}$ de profundidade), no centro (profundidade aproximada de $2,50 \mathrm{~m}$ ) e próxima à saída (aproximadamente 2,25 m). Coletaram-se águas da superfície e a um metro de profundidade.
No córrego da Lagoa, principal contribuinte para a represa, dois locais de coleta, sendo um deles com um fluxo de água sem muita movimentação, encontrando ao seu redor uma grande plantação de café $\left(21^{\circ} 25,238^{\prime} \mathrm{S}\right.$ e $46^{\circ}$ $15,899^{\prime}$ W) e o outro próximo a uma queda d'água (cachoeira), com maior turbulência, que já se encontra dentro dos limites da Fazenda Lagoa $\left(21^{\circ} 24,890^{\prime} \mathrm{S}\right.$ e $46^{\circ}$ $\left.15,697^{\prime} \mathrm{W}\right)$. Foi feita uma coleta também na nascente $\left(21^{\circ} 25,704^{\prime} \mathrm{S}\right.$ e $46^{\circ} 16,034^{\prime}$ W) deste córrego, que se encontra no meio de mata fechada. Essas coletas foram realizadas e armazenadas em frasco de polietileno $(250 \mathrm{~mL})$.

\section{Preparo das amostras}

As amostras para análise de sulfeto foram filtradas no local de coleta, com membrana de $0.45 \mu \mathrm{m}$ e adicionaram-se $0,20 \mathrm{~mL}$ (4 gotas) de acetato de zinco 220 $\mathrm{g} \mathrm{L}^{-1}$ para cada $100 \mathrm{~mL}$ de amostra para conservação do sulfeto. Já para a conservação do sulfato, as amostras foram mantidas a baixas temperaturas $\left(4^{\circ} \mathrm{C}\right) \mathrm{e}$ filtradas com membrana de $0.45 \mu \mathrm{m}$ no laboratório (CLESCERI, 1998). 


\section{Medidas dos Parâmetros Físico- Químicos}

Os parâmetros físico-químicos: $\mathrm{pH}$, potencial redox (Eh), condutividade elétrica, temperatura, foram medidos no instante da coleta com equipamentos portáteis (PEREIRA, 1987).

Para a medida de $\mathrm{pH}$ empregou-se eletrodo de vidro combinado com eletrodo de referência de calomelano saturado, a calibração foi feita com duas soluções tampão de pH 4,00 e 7,00 (WTW $\left.{ }^{\circledR}\right)$. O potencial redox foi medido com eletrodo de platina combinado com eletrodo de calomelano saturado, a calibração foi feita com solução Zobell, $184 \quad \mathrm{mV}$ (NORDSTROM, 1998). A condutividade foi medida com célula condutométrica de platina de $1 \mathrm{~cm}^{2}$, a calibração foi feita com solução de $\mathrm{NaCl} 30 \mathrm{mg} \mathrm{L}^{-1}$, condutividade de $74,0 \mu \mathrm{S} / \mathrm{cm}$.

\section{Determinação de sulfato}

A determinação de sulfato foi feita por método turbidimétrico baseado na reação de íons sulfato com íons bário em meio ácido relatado por Clesceri et al. (1998) e modificado para um sistema de análise em fluxo contínuo, (FIA) por Zagatto et al. (1981) (fig. 1).

A solução aquosa de cloreto de bário a $5,0 \% \mathrm{~m} / \mathrm{v}$ em álcool polivinílico (PVA) a $0,05 \% \mathrm{~m} / \mathrm{v}$ foi preparada suspendendo $250 \mathrm{mg}$ de PVA em aproximadamente $100 \mathrm{~mL}$ de água sob agitação contínua. Adicionaram-se 300 mL de água em ebulição. Quando uma solução clara foi obtida, adicionaram-se $25 \mathrm{~g}$ de $\mathrm{BaCl}_{2} \cdot 2 \mathrm{H}_{2} \mathrm{O}$ e após dissolução completouse o volume com água a $500 \mathrm{~mL}$. Se houver formação de precipitado (provavelmente, polimerização do PVA), a solução deverá ser filtrada. A solução é estável por algumas semanas (ZAGATTO et. al., 1981).

Neste método ocorre formação de sulfato de bário gerando turbidez no sistema, a qual é medida em espectrofotômetro a $410 \mathrm{~nm}$. Uma vez que há precipitação do produto formado na cubeta, ocorre instabilidade da linha de base e por este motivo emprega-se uma solução de EDTA $0,3 \% \mathrm{~m} / \mathrm{v}$ em $\mathrm{NaOH}$ 0,07 M para solubilizar o precipitado e restabelecer a linha base do sistema. Os padrões de sulfato foram feitos com sulfato de ferro II, sendo a solução estoque de 100 ppm de $\mathrm{SO}_{4}{ }^{2-}$. 


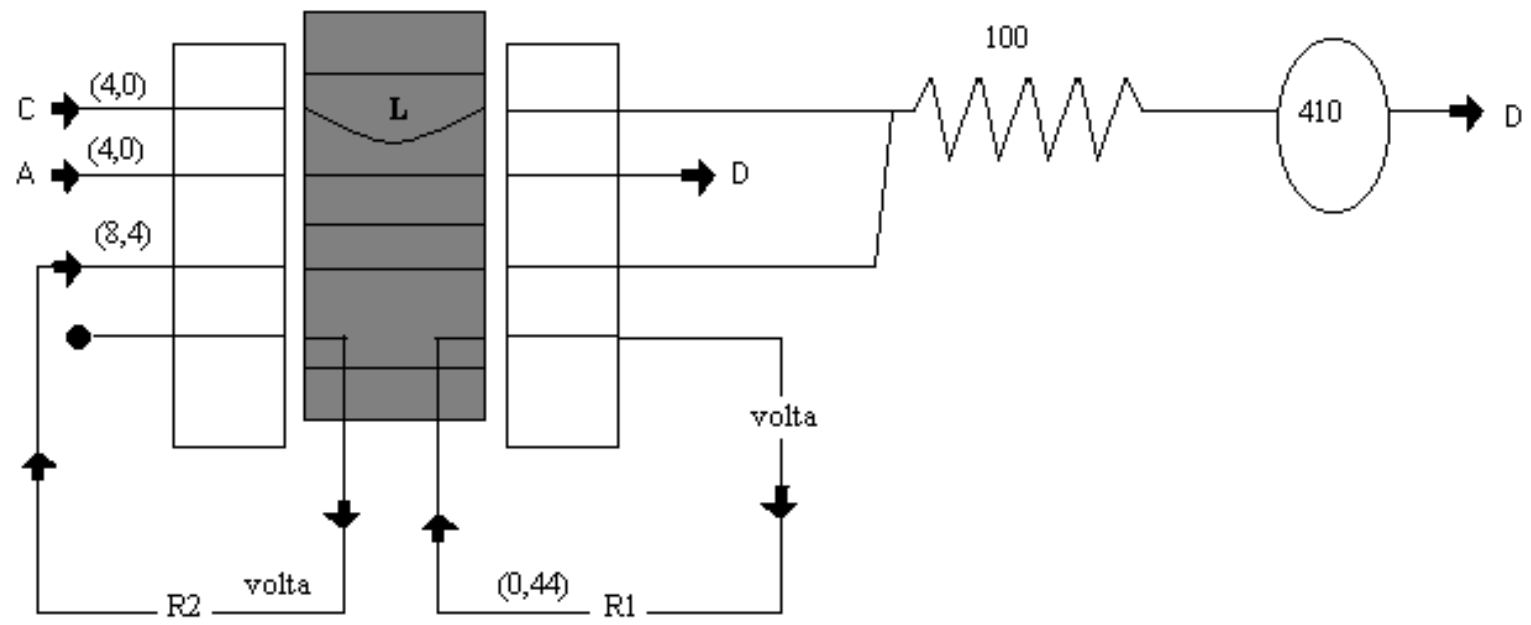

Figura 1: Módulo do Sistema FIA para análise de sulfato: A: Amostras; C: carregador $\left(\mathrm{H}_{2} \mathrm{O}\right)$; D: descarte; R1: solução aquosa de $\mathrm{BaCl}_{2} \cdot 2 \mathrm{H}_{2} \mathrm{O}$ a $5,0 \%$ em álcool polivinílico (PVA) a $0,05 \% \mathrm{~m} / \mathrm{v}$; R2: solução de EDTA 0,3\% m/v em NaOH 0,07 M; L: alça de amostragem ( v = $502 \mu \mathrm{l}$ ); os valores entre parênteses são as vazões dos cabos em $\mathrm{ml} / \mathrm{mim}$.

\section{Determinação de Sulfeto}

O sulfeto foi determinado em sistema FIA com detecção espectrofotométrica baseada na reação do sulfeto de hidrogênio, em meio ácido e na presença de cloreto férrico, com duas moléculas de N,N-diethyl-pphenylenediamine para formar o azul de metileno (fig 2). A cor resultante foi lida a 660 nm (CLESCERI et al., 1998 \& KUBAN, 1992).

A solução de N,N-diethyl-pphenylenediamine foi preparada pesando- se $500 \mathrm{mg}$ do reagente, dissolvendo-o em $40 \mathrm{~mL}$ de $\mathrm{HCl} 12 \mathrm{M}$ e então diluindo para $250 \mathrm{~mL}$ em balão volumétrico (KUBAN, 1992 \& CLESCERI et al., 1998).

A solução de cloreto férrico hexahidratado foi preparada em balão de $500 \mathrm{~mL}$ dissolvendo-se $6,65 \mathrm{~g}$ do reagente em aproximadamente $450 \mathrm{ml}$ de $\mathrm{HCl} 0,20$ M e completando-se com água (CLESCERI et al., 1998).

Os padrões de sulfeto foram preparados a partir de Sulfeto de Sódio nonahidratado, tendo uma solução estoque com a concentração de 100 ppm de $\mathrm{S}^{2-}$. 


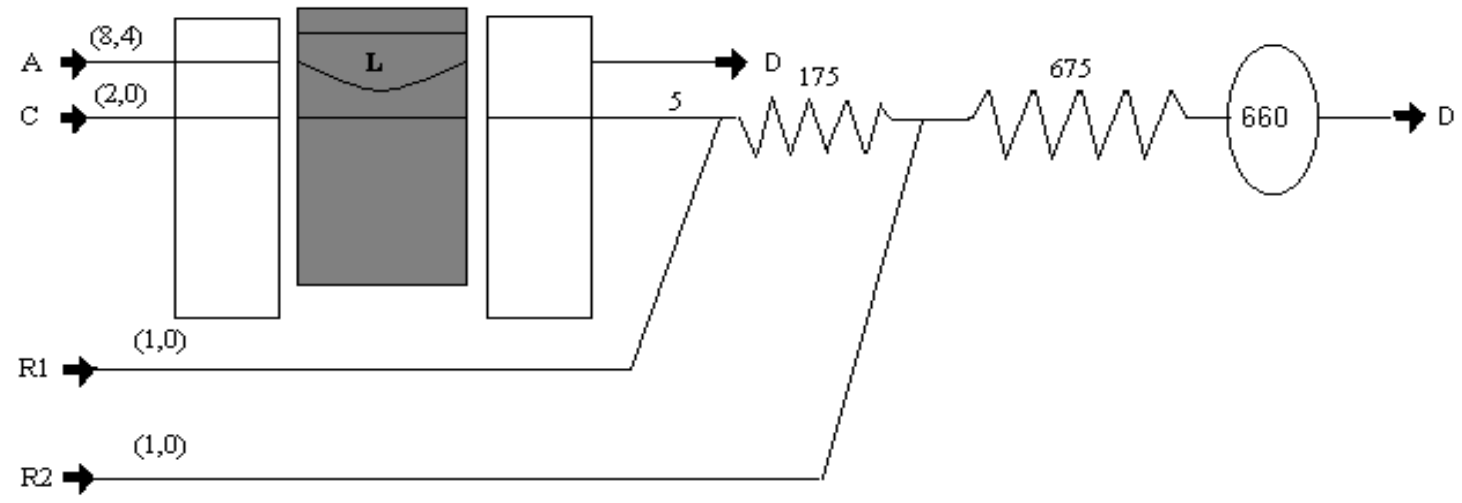

Figura 2: Módulo do sistema FIA para análise de sulfeto: A: Amostras fixadas com acetato de zinco $5 \% \mathrm{~m} / \mathrm{v}$; C: carregador $\left(\mathrm{H}_{2} \mathrm{O}+\right.$ acetato de zinco $\left.5 \% \mathrm{~m} / \mathrm{v}\right)$; D: descarte; R1: solução de N,N-diethyl-p-phenylediamine $2 \mathrm{~g} / \mathrm{L}$ em $\mathrm{HCl} 6 \mathrm{M}$; R2: solução de cloreto de ferro hexahidratado em $\mathrm{HCl} 0,20 \mathrm{M} ; \mathrm{L}=$ alça de amostragem $(\mathrm{v}=1709 \mu \mathrm{l})$; Os valores entre parênteses são as vazões dos cabos em $\mathrm{ml} / \mathrm{mim}$.

\section{RESULTADOS E DISCUSSÃO}

\section{Parâmetros analíticos}

A fig. 3 apresenta os registros de sinais do sistema FIA para os padrões de sulfato e três amostras do mês de setembro, mostrando uma boa repetibilidade das análises. Para a determinação obteve-se uma equação da reta igual a: $\mathrm{A}=0,0042 \mathrm{C}$ - 5E-05 com um $\mathrm{R}^{2}$ de 99,97\%, tendo como figuras de mérito um limite de quantificação (LQ) de 3,57 ppm e limite de detecção (LD) de 1,07 ppm.

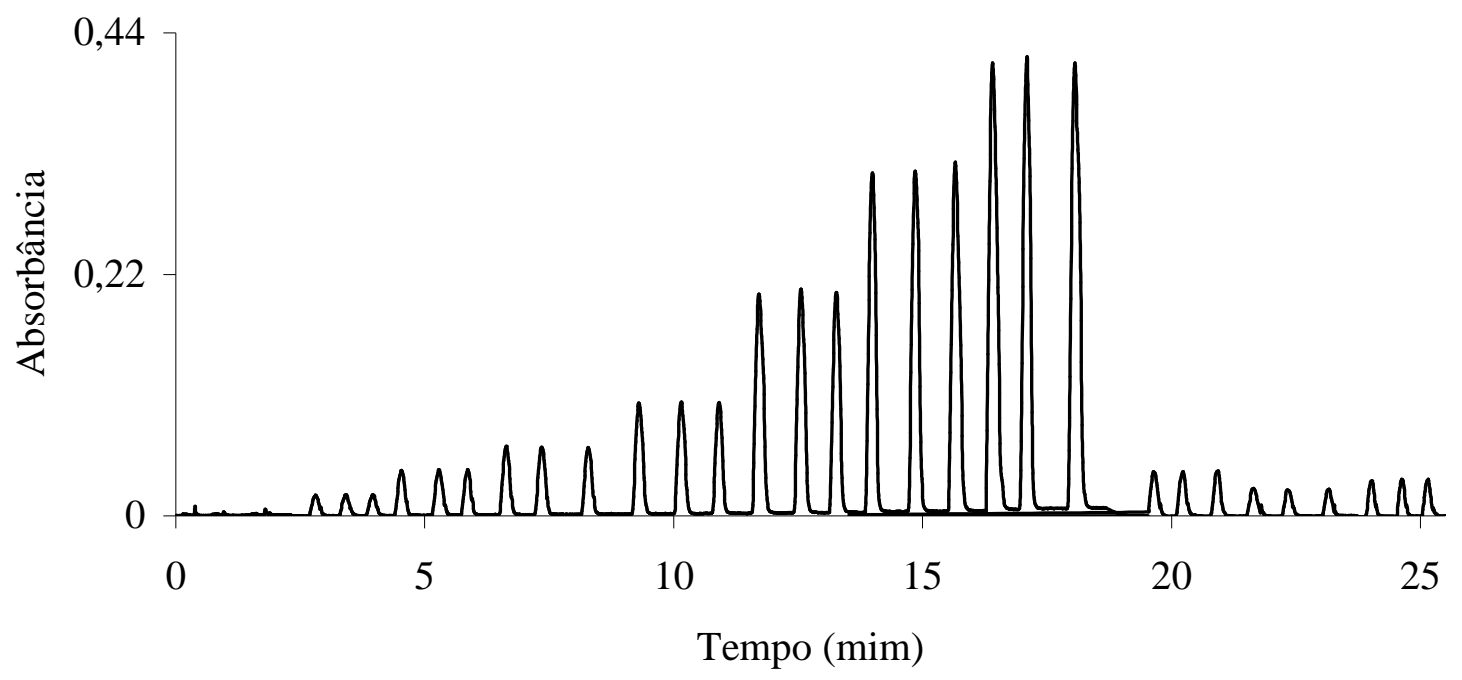

Figura 3: Registro de sinais, em triplicata, para curva analítica de sulfato com concentração de 0,$0 ; 5,0 ; 10,0 ; 15,0 ; 25,0 ; 50,0 ; 75,0$ e $100,0 \mathrm{ppm}$ de $\mathrm{SO}_{4}{ }^{2-}$ e registro de três amostras do mês de setembro, da esquerda para a direita respectivamente, leituras em $410 \mathrm{~nm}$. 
A fig. 4 apresenta os registros de sinais do sistema FIA para os padrões de sulfeto, também com boa repetibilidade. Para determinação obteve-se uma equação da reta igual a: $\mathrm{A}=0,0004 \mathrm{C}-0,0002$, com um $\mathrm{R}^{2}=99,85 \%$, tendo como figuras de mérito um LQ de 12,91 ppb e LD de 3,87 ppb.

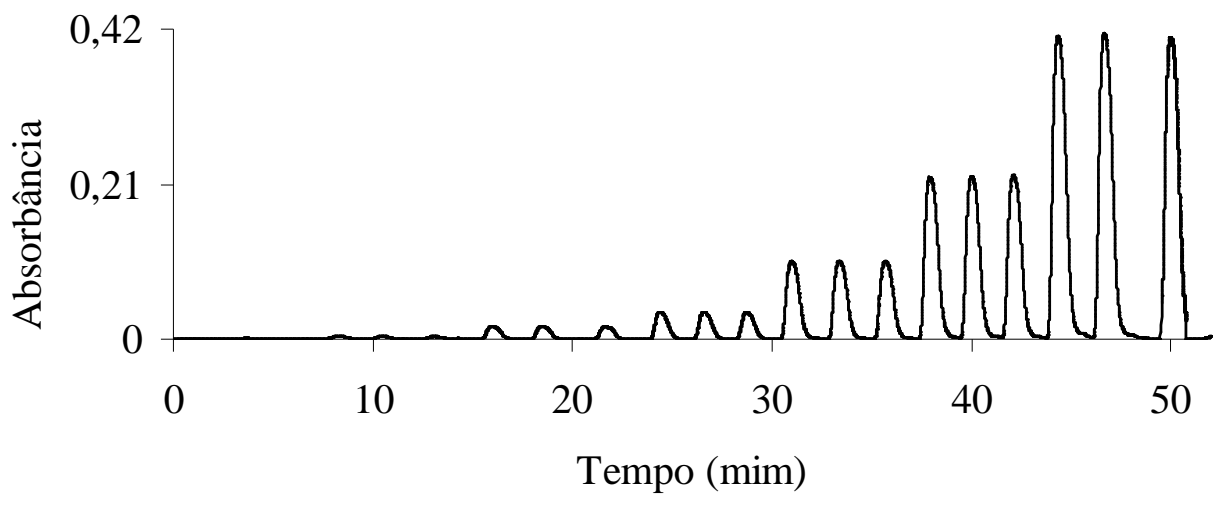

Figura 4: Registro de sinais, em triplicata, para curva analítica de sulfeto com concentração de 0,$0 ; 10,0 ; 50,0 ; 100,0 ; 250,0 ; 500,0$ e $1000 \mathrm{ppb}$ de $\mathrm{S}^{2-}$, da esquerda para a direita respectivamente, leituras em $660 \mathrm{~nm}$.

Concentrações dos compostos de enxofre

Segundo Wetzel (1983) as concentrações de sulfato em lagos com águas oxigenadas é cerca de 5 a 30 ppm, média de 11 ppm, encontrando em alguns lagos africanos concentrações ligeiramente inferiores a 1 ppm e em lagos halinos ricos em sulfato, mais de $50 \mathrm{~g} \mathrm{~L}^{-1}$.

No presente trabalho a concentração média geral de sulfato (fig. 5) foi de 13,47 ppm e portanto este ambiente mostra-se como um sistema formado recentemente e em estágio de senescência, caracterizados pela pouca profundidade e alta evaporação, encontrando concentrações mais altas dos íons (ESTEVES, 1998).
Segue uma abordagem das variações sazonais da concentração de sulfato no ambiente estudado: no mês de abril, em todos os pontos de coleta (fig. 5) obtiveram-se concentrações altas comparadas a dos outros meses, com média de 46,42 ppm, estas concentrações estão relacionadas com a grande pluviosidade ocorrida na região até este mês e também com o grande aporte de matéria orgânica que chega aos locais estudados junto às chuvas, isto se justifica, pois uma das principais fontes de enxofre em águas naturais é a precipitação atmosférica úmida e seca (WETZEL, 1983). 


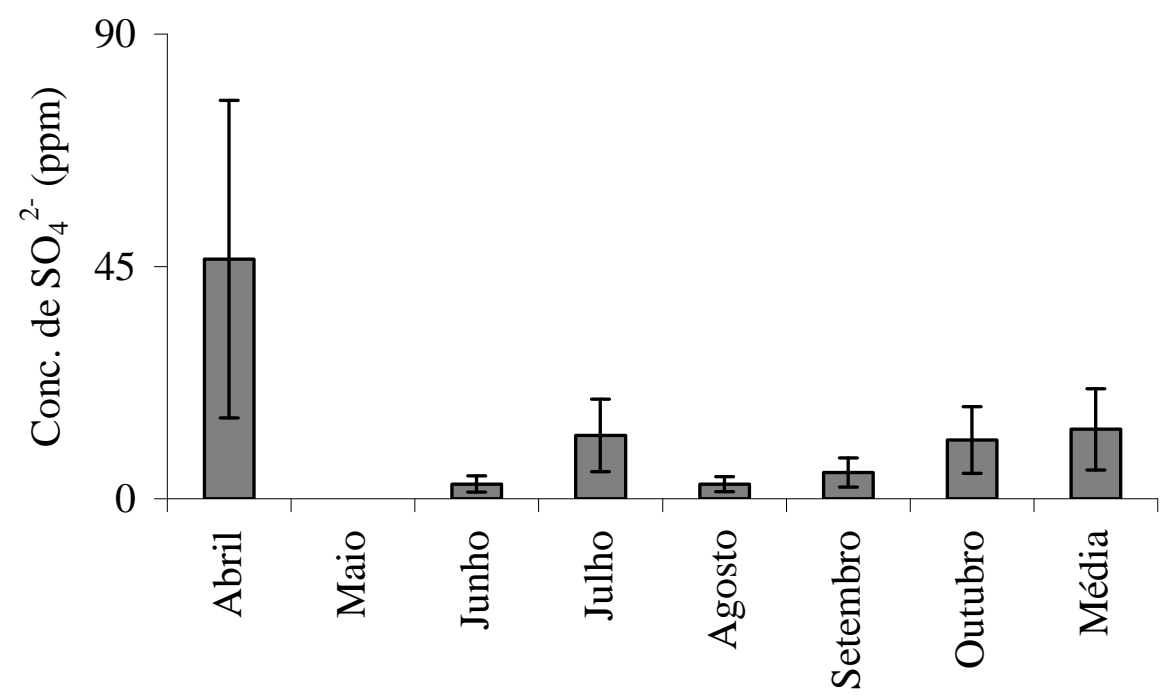

Figura 5: Colunas: variações sazonais das concentrações médias de sulfato; Barras verticais: desvios padrões $(n=9)$.

Nos meses subseqüentes, comparadas as de abril, evidenciadas pela começando por maio, em que não foi baixa pluviosidade (fig.6) (COPASA, detectado sulfato em nenhum dos locais 2004) do período e conseqüente queda da coletados, até setembro, foram obtidas ciclagem dos íons, incluindo o sulfato. concentrações menores deste analito,

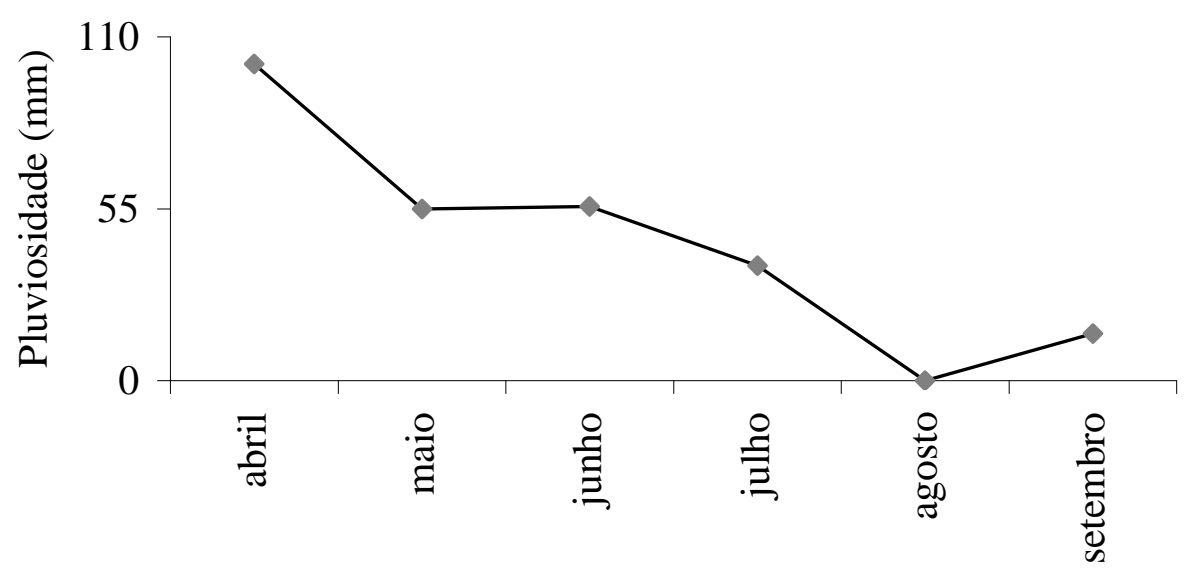

Figura 6: Valores referentes à média de pluviosidade no período de abril a setembro da região de Alfenas, MG. Fonte: COPASA - Alfenas.

Já no mês de outubro, quando se principalmente no ponto 1 (fig. 7), iniciou a estação chuvosa, as mostrando a entrada do sulfato na represa, concentrações são um pouco maiores, através das águas vindas do córrego. 


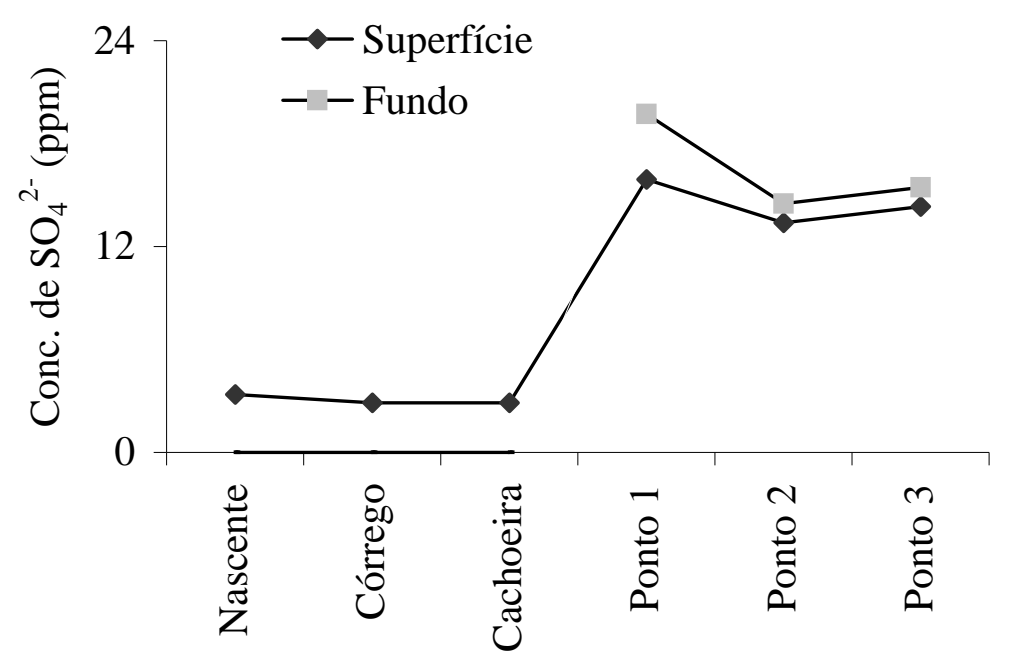

Figura 7: Média da concentração de sulfato ( $\mathrm{ppm}$ ) nos pontos de coleta no mês de outubro.

Foram observadas concentrações baixas para sulfeto (5,5 a 14,25 ppb) encontrada nos pontos para os meses de agosto a outubro. Este fato era esperado, pois de acordo com Wetzel (1983) e Esteves (1998), em ambiente óxido o $\mathrm{H}_{2} \mathrm{~S}$ é instável e rapidamente oxidado, tanto química como biologicamente. Assim, há pouco $\mathrm{H}_{2} \mathrm{~S}$ nas zonas arejadas dos sistemas aquáticos. Destaca-se também a nocividade do $\mathrm{H}_{2} \mathrm{~S}$ que pode propiciar condições ambientais desfavoráveis à vida aquática, podendo provocar inclusive grandes mortandades de peixes, e isto ocorre mesmo em ecossistemas desprovidos de qualquer forma de poluição, como na região amazônica.

Segue uma abordagem das variações das concentrações em função dos pontos de coleta: nota-se que a concentração de sulfato aumenta ao longo dos pontos: nascente, córrego, cachoeira progressivamente até chegar na represa (fig. 8), isto pode ser devido ao aumento da vazão e ao carreamento de matéria orgânica que vai ocorrendo ao longo do percurso do córrego.

$\mathrm{Na}$ represa encontraram-se valores superiores na superfície comparados aos a $1 \mathrm{~m}$ de profundidade (fig. 8). Isso não ocorreu no ponto 1 devido à menor profundidade deste local (aproximadamente 1,25m), e também por ser o local de entrada de água vinda do Córrego da Lagoa (principal contribuinte para este ecossistema), observando-se uma maior circulação dos íons e mostra-se como um local bastante arejado. 


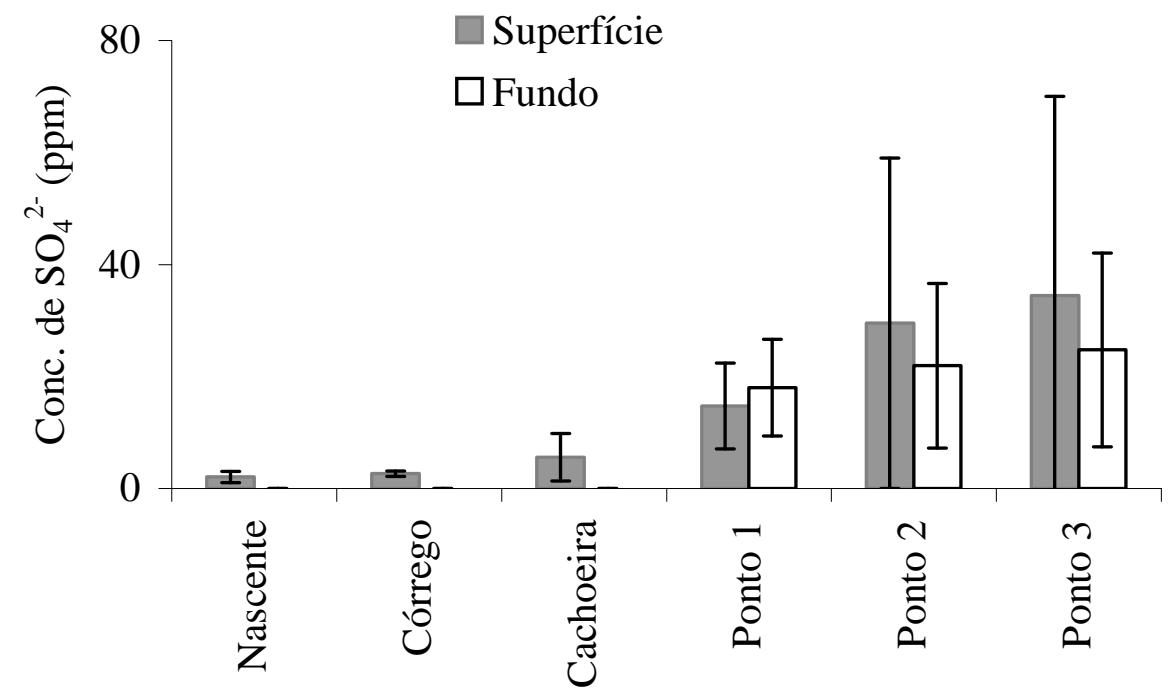

Figura 8: Colunas: Média das concentrações de sulfato (ppm) em cada ponto em todo período de coleta; Barras verticais: desvios padrões $(n=6)$.

Nos pontos 2 e 3 nota-se maiores concentrações de sulfato nos estratos superiores do que nos mais profundos. Como o sulfato é a principal forma oxidada do enxofre encontrada na natureza, é coerente que em extratos mais profundos, com pouca oxigenação da água, ocorra menor concentração do íon.

Para o sulfeto, observa-se um processo oposto ao do sulfato, i.é, encontram-se valores superiores na profundidade de 1 metro comparada aos da superfície (fig. 9). Nos extratos mais profundos as condições redutoras propiciariam a geração de sulfetos, quer por redução dissimilatória do sulfato, quer por putrefação, que seriam, pelo menos em parte, reoxidados a sulfato ao migrarem por difusão para os extratos superiores, mais oxidantes (KRUSCHE, 1995). Também pode ser observada na Figura 10 concentração mais alta, comparada aos outros pontos, para a nascente, este fato se explica, pois de acordo com Clesceri et al. (1998), o sulfeto é encontrado principalmente em nascentes devido às águas serem de origem de águas subterrâneas, ricas em sulfetos. 


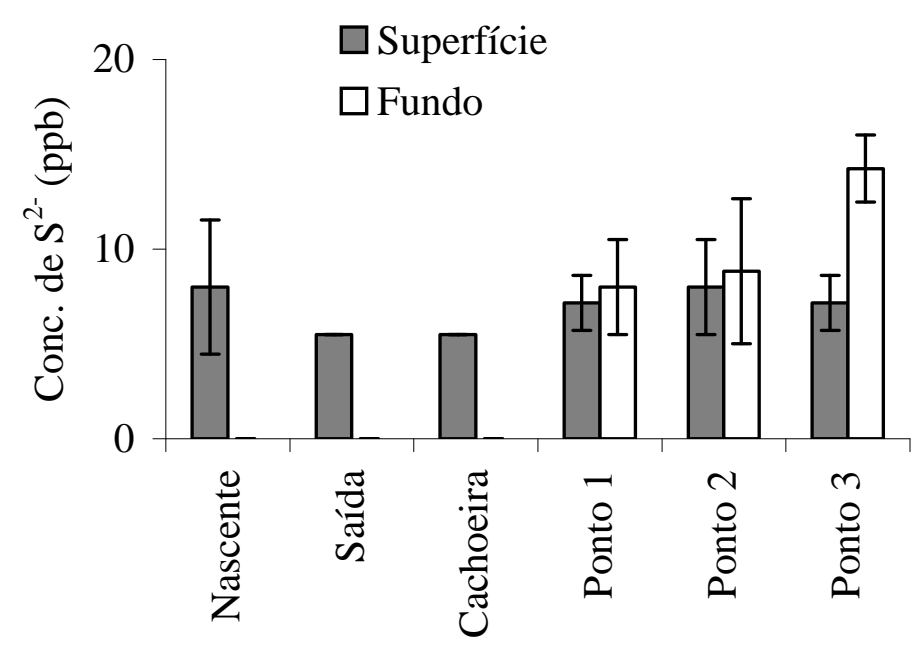

Figura 9: Média das concentrações de sulfeto (ppb) em cada ponto nos meses de coleta. Barras verticais: desvios padrões $(n=3)$.

Correlações com os parâmetros físicoquímicos

Analisando os parâmetros físicoquímicos e comparando-os aos valores encontrados para os analitos estudados, observa-se uma relação entre os valores de condutividade elétrica e os de sulfato (fig.
10). A condutividade elétrica apresenta relação proporcional à concentração de substâncias iônicas dissolvidas na água (NASCIMENTO, 1997) e isto explica sua relação com o sulfato que é a forma predominante de enxofre dissolvido na água (WETZEL, 1983).

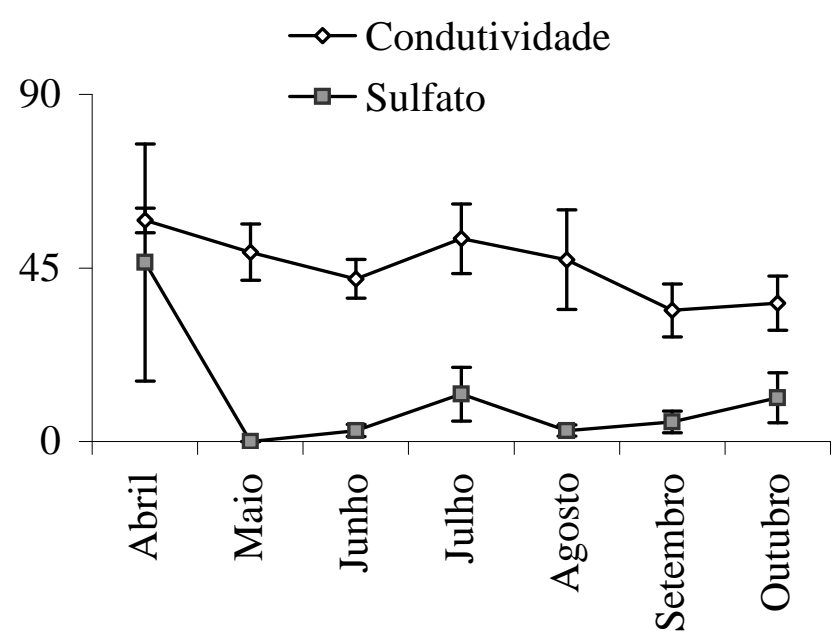

Figura 10: Comparação da média das concentrações encontradas para condutividade elétrica $(\mu \mathrm{S} / \mathrm{cm})$ com a média das concentrações de sulfato (ppm) nos meses de coleta. Barras verticais: desvios padrões $(n=9)$. 
Em relação aos valores de temperatura da água que influencia processos biológicos, reações químicas e bioquímicas, estando intimamente relacionada com a solubilidade dos gases e sais minerais (NASCIMENTO, 1997), observou-se que no mês de abril registrouse uma média de temperatura nos pontos estudados de $21,1^{\circ}$ C. Já de maio a agosto registrou-se uma média de temperaturas de aproximadamente $16,8^{\circ} \mathrm{C}$, ocorrendo uma alta em setembro $\left(24,6^{\circ} \mathrm{C}\right)$ e uma queda em outubro $\left(20,6^{\circ} \mathrm{C}\right)$ devido às chuvas do período. No local estudado, as variações de temperatura (fig. 11) ajudam a entender a sazonalidade que é determinante para a ciclagem de elementos e nutrientes importantes para o ecossistema, como o sulfato que se encontra no presente trabalho menores valores nos meses com temperaturas mais baixas e maiores a partir do aumento da temperatura.

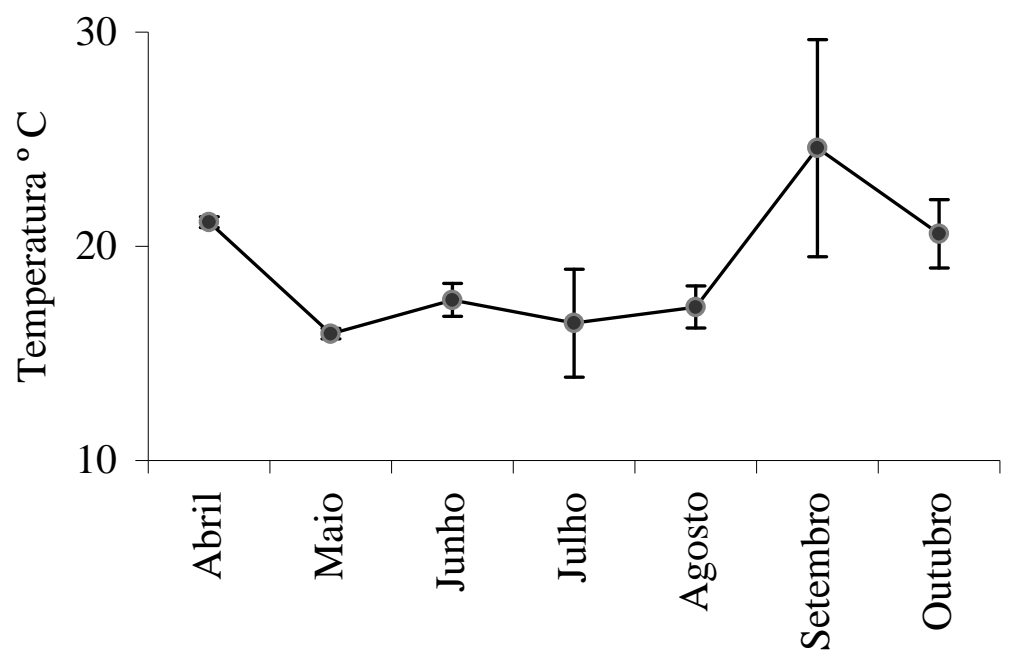

Figura 11: Média dos valores de temperatura $\left({ }^{\circ} \mathrm{C}\right)$ da água nos meses estudados. Barras verticais: desvios padrões $(n=9)$.

As médias dos valores de potencial redox (Eh) (fig. 12) variaram entre 116, $33 \mathrm{mV} \pm$ 14,05 em setembro a $165,00 \mathrm{mV} \pm 13,27$ em julho e não demonstraram uma correlação evidente com as concentrações dos analitos estudados, assim como os de pH. Em ambos os parâmetros, os valores são próximos aos obtidos em outros lagos semelhantes (KRUSCHE, 1995 \& MOZETO, 1997). 


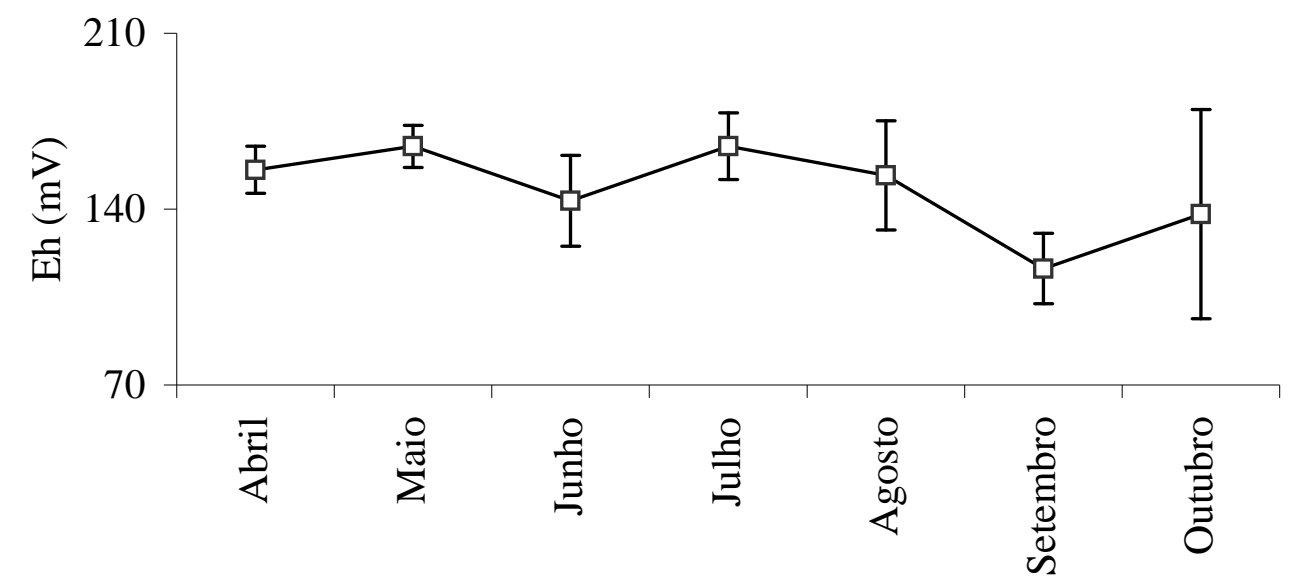

Figura 12: Média dos valores de Eh (potencial redox) nos meses de coleta. Barras verticais: desvios padrões $(n=9)$.

Em ecossistemas aquáticos os 0,13) dos valores encontrados dos locais valores de pH podem variar entre 6 a 9 de nos meses em estudo são apresentadas na acordo com a legislação (MINISTÉRIO, fig. 13 e mostram pouca variação ao longo 1986). As médias $(5,87 \pm 0,37$ a $6,73 \pm \quad$ dos meses.

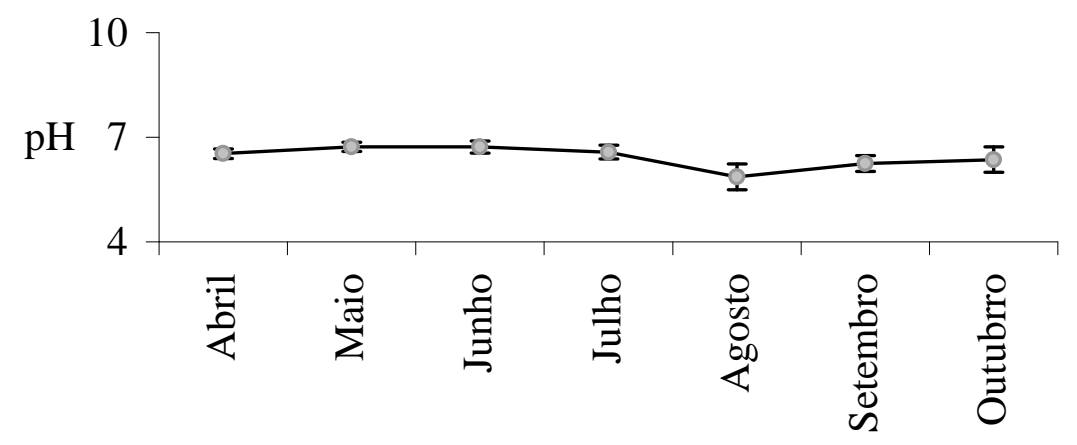

Figura 13: Média dos valores de $\mathrm{pH}$ dos pontos nos meses de coleta. Barras verticais: desvios padrões $(n=9)$.

$\mathrm{Na}$ seqüência foram feitas algumas metais presentes no ecossistema. Na fig. 14 inferências sobre possíveis interações entre estão apresentados concentrações de ferro, os teores de compostos de enxofre e alguns alumínio (PESSÔA, 2004) e sulfato. 


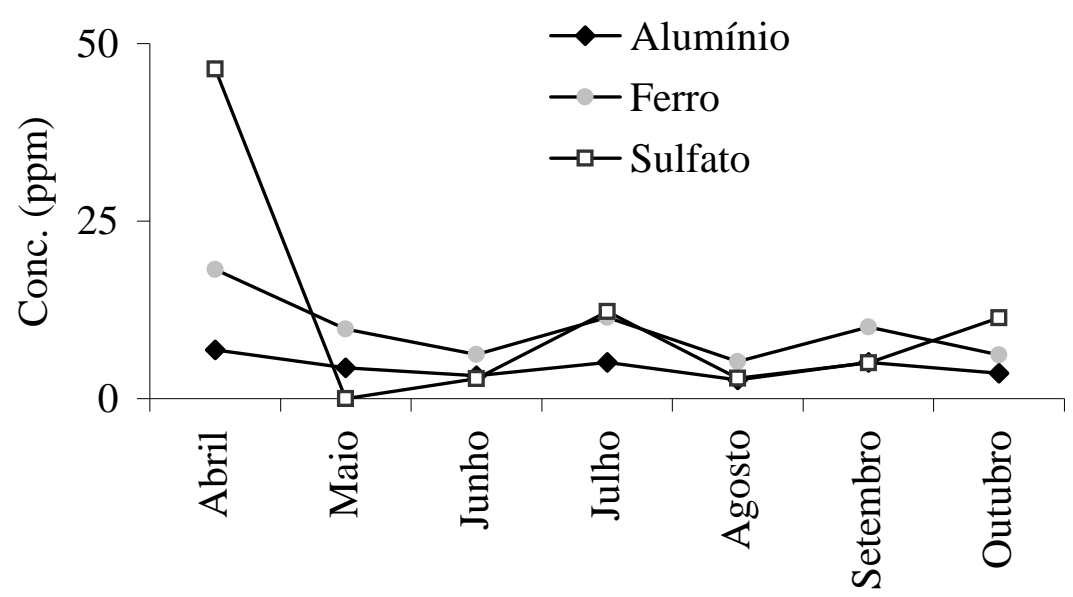

Figura 14: Média das concentrações de Alumínio, ferro e sulfato nos meses de coleta, medidas em ppm. As concentrações de alumínio e ferro estão multiplicadas por um fator 10 para melhor comparação dos resultados.

O alumínio e o ferro são afetados pelas condições de oxirredução no lago e juntamente com outros metais são precipitados pela ação de bactérias, descrito em Esteves (1998), estando relacionada, assim como o ferro, com a concentração dos compostos de enxofre (sulfato e sulfeto) que são essenciais para o metabolismo dessas bactérias denominadas dessulfurantes.

Os íons ferro que se encontram próximo ao sedimento e em determinadas profundidades reagem com $\mathrm{O} \quad \mathrm{H}_{2} \mathrm{~S}$ formando $\mathrm{FeS}$ insolúvel que vai para o sedimento. Na fig. 15 observamos uma relação inversa entre os níveis de ferro e sulfeto, isso quer dizer, que quando ocorre um aumento da concentração de sulfeto observa-se a diminuição da concentração de ferro e vice-versa. Este fato ajuda a explicar a ocorrência de baixas concentrações de sulfeto na coluna d'água, principalmente na superfície, e concentrações maiores de ferro, mostrando ser um ambiente rico em íons ferro que além de serem precipitados para o sedimento, ainda são encontrados livres na coluna d'água. 


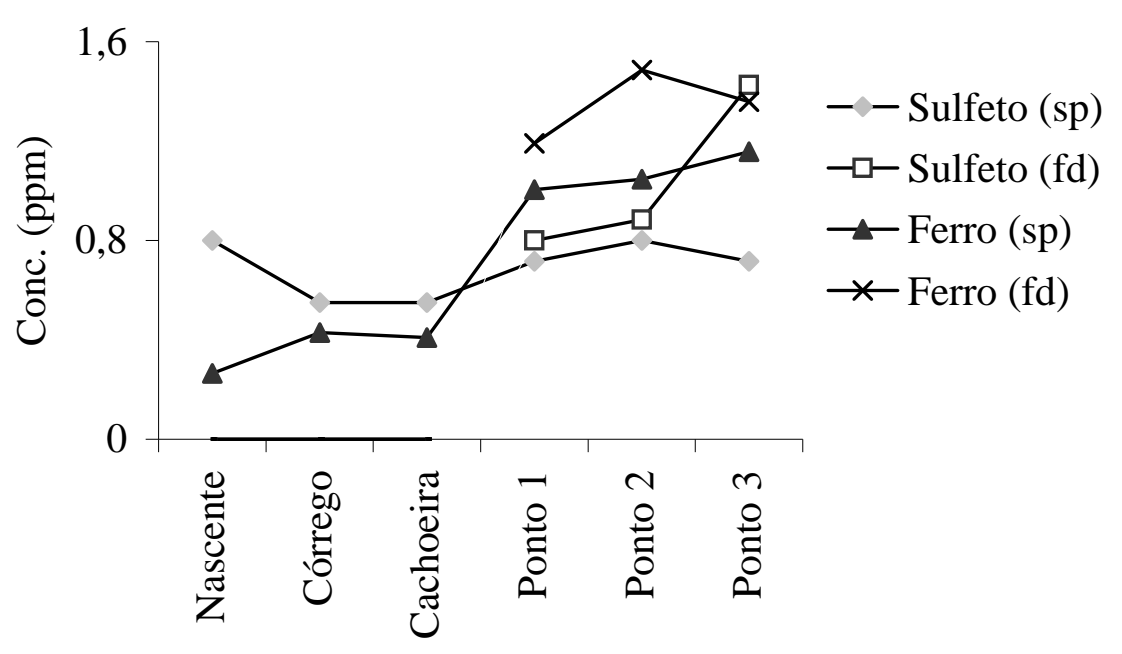

Figura 15: Média das concentrações de ferro e sulfeto nos locais de coleta no período em estudo, medidas em ppm ( $\mathrm{sp}$ - superfície, fd - fundo). As concentrações de sulfeto estão multiplicadas por um fator 100 para melhor comparação dos resultados.

$\mathrm{O}_{2} \mathrm{~S}$ é encontrado livre na água após quase todo $\mathrm{Fe}^{2+}$ ter sido precipitado sob a forma de FeS, deste modo estando livre, o sulfeto próximo ao sedimento permite a liberação de outros metais, formando sulfetos ainda mais insolúveis que o do ferro (WETZEL, 1983). Isto reforça a importância do ciclo do enxofre influenciando outros ciclos de nutrientes importantes e também de alguns elementos-traços como o ferro e o alumínio.

\section{CONCLUSÃO}

As metodologias aplicadas para as determinações das amostras foram satisfatórias e podem ser utilizadas para quantificação de sulfato e sulfeto também em outros ambientes lacustres.
As concentrações para sulfato nos pontos de coleta aumentam à medida que se distancia da nascente, encontrando na represa, concentrações mais altas comparadas aos outros pontos, isto se deve a represa ser um ambiente com menos circulação de água e maior precipitação de espécies químicas.

A partir dos dados obtidos para os analitos estudados, percebeu-se uma estratificação da coluna d'água na represa, mesmo esta não sendo muito profunda (máximo 2,5 m), evidenciado pelas concentrações encontradas, na superfície e a $1 \mathrm{~m}$ de profundidade, dos analitos estudados.

Existe correlação entre os teores de compostos de enxofre e os parâmetros físico-químicos, bem como com os teores dos metais, ferro e alumínio, e também 
foram notadas variações sazonais típicas do ecossistema.

Os processos de redução e oxidação do enxofre constituem importantes mecanismos de reciclagem do elemento na represa da Fazenda Lagoa, podendo postular-se que sejam típicos desse ambiente, i.é., lagoa mesotrófica devido às concentrações de nutrientes como os compostos de enxofre serem medianas e por consequiência haver uma produção orgânica média (ESTEVES, 1998).

\section{REFERÊNCIAS BIBLIOGRÁFICAS}

Clesceri, L. S.; Greenberg, A. E.; Eaton, A. D.; 1998, Standard methods for the examination of water and wastewater, Washington: American Public Health Association, 4-162-4-173.

Companhia da tecnologia de saneamento ambiental (COPASA); Relatório totais pluviométricos mensais 2004, Alfenas, MG.

Crnkovic, P. M. \& Jacintho, A. O.; 2002, Emprego de reagente de suspensão em sistema de injeção em fluxo: determinação espectrofotométrica de sulfato em águas naturais. Quím. Nova, 25, 254.
Esteves, F. A.; 1998, Fundamentos de Limnologia, Rio de Janeiro, Editora Interciência, 244-254.

Komarnisky, L. A.; Christopherson, R. J.; Basu, T. K.; 2003; Sulfur: its clinical and toxicologic aspects, Nutrition, 19, 54.

Krusche, A. V. \& Mozeto, A. A.; 1995, Tese de doutorado: Aspectos do ciclo biogeoquímico do enxofre ao longo do rio $\underline{\text { Solimões - Amazonas e em um de lago de }}$ várzea - lago do Calado, Manacapuru, $\underline{\mathrm{AM}}$, Universidade Federal de São Carlos, Brasil.

Kuban, V.; Dasgupta, P. K.; Marx, J. N.; 1992, Nitroprusside and methylene blue methods for silicone membrane differentlated flow injection determination of sulfide in water and wastewater, Anal. Chem., 64, 37.

Martins, C. R.; Andrade, J. B. de.; 2002; Química atmosférica do enxofre (IV): emissões, reações em fase aquosa e impacto ambiental, Quím. Nova, 25, 259.

Ministério do desenvolvimento urbano e meio ambiente 1986; Resolução n. ${ }^{\circ} 20$ de 18 de Junho de 1986. D.O.U. Executivo, 11356. 
Miró, M.; Estela, J. M.; Cerdà, V.; 2004, Application of flowing-stream techniques to water analysis: Part II. General quality parameters and anionic compounds: halogenated, sulphur and matabolloid species. Talanta, 62, 3 .

Mozeto, A. A.; Krusche, A. V.; Luccas, P. O.; 1997, Aspectos do ciclo biogeoquímico do enxofre em uma lagoa marginal da área do rio Moji-Guaçu - Estação ecológica de Jataí, Luis Antônio, SP, Geochim. Brasilien., 11, 231.

Nascimento, L. V.; 1997, Anexo 2: Características dos principais parâmetros para a determinação da qualidade da água. Ministério do meio ambiente. Disponível em:

http://www.mma.gov.br/port/srh/acervo/pu blica/doc/zoneamen/anexo2.pdf>, acessada em novembro de 2004.

Nordstrom, D. K. \& Wilde, F. D.; 1998, Reduction-oxidation potencial (electrod method), Geolog. Surv., 9, 1.

Pereira, B. E. B.; Yassuda, E. R.; Martins, J. M. et al.; 1987, Técnica de abastecimento e tratamento da água, 70.

Pessôa, G. S.; Oliveira, F. S. G.; Luccas, P. O.; 2004, Trabalho de conclusão de curso: Avaliação do teor de elementos-traço em uma represa na Fazenda Lagoa, município de Monte Belo, Minas gerais, Escola de Farmácia e Odontologia de Alfenas Centro Universitário Federal, Brasil.

Wetzel, R. G.; 1983, Limnologia, USA, Sauders College Publishing, 379-395.

Weyland, M. C. V.; 1990, Dissertação de mestrado: Fitogeografia e conservação de florestas em Monte Belo, Minas Gerais Estudo de caso: Fazenda Lagoa, Universidade Federal do Rio de Janeiro, Brasil.

Zagatto E. A. G.; Jacintho A. O.; Reis B. F.; Krug F. J.; Bergamin $F^{o}$ H.; Pessenda L. C. R.; Mortatti J., Giné M. F.; 1981, Manual de análise de plantas e água empregando sistema de Injeção em fluxo. Centro de energia nuclear na agricultura, Piracicaba, Brasil.

\section{AGRADECIMENTOS}

Agradeço a Maria Cristina Vieira Weyland, proprietária e coordenadora da Fazenda Lagoa, Instituto Sul-minerio de Proteção Ambiental, por nos ceder o local para a realização do projeto e a Efoa/Ceufe pelo incentivo e apoio à pesquisa dada aos alunos e todos àqueles que de alguma forma fizeram parte desse trabalho. Obrigado. 